\title{
The mental representation of faces: Spatial and temporal factors
}

\author{
J. DAVIDOFF \\ Neuropsychology Unit, Radcliffe Infirmary, Oxford, England
}

\begin{abstract}
Three experiments are reported on the mental representation of faces with respect to the production of a face superiority effect. The effects of varying spatial position of the features and type of accompanying feature were investigated. Variations in attention to facial versus nonfacial features were considered by regression analyses, allowing an assessment of which was the more facelike of any two displays. Such regression analyses may have application to other recognition tasks if attention is divided between aspects of the display. Two further experiments explored the role of exposure duration in face superiority effects. The relationship of the results to models of face recognition is considered.
\end{abstract}

The processing of visual displays is critically dependent on their spatial arrangement. The goodness of a pattern (Koffka, 1935) affects recognition (Checkosky \& Whitlock, 1973), reproduction (Bell \& Handel, 1976), and the functional capacity of temporary visual storage (Fryklund, 1975). Spatial arrangement is also important for meaningful displays. The recognition of faces (Homa, Haver, \& Schwartz, 1976; van Santen \& Jonides, 1978), objects (Weisstein \& Harris, 1974), and scenes (Biederman, 1972) are all impaired by spatial rearrangement. The precise nature of the rearrangement necessary to effect an impairment will depend on the particular object or scene, and is the primary concern of the present study with respect to faces.

Loftus, Nelson, and Kallman (1983) propose that scenes are processed in two stages. Holistic information-the gist or schema-is extracted first, and this is followed by a search for specific features. The schema is achieved rapidly during the first fixation. It then activates some representation in long-term storage presumably held in a pictorial data store (Seymour, 1979) that is part of the presumed pictorial memory system (Paivio, 1971). A search is then initiated for specific features of the material held in temporary storage. The same should also apply to faces. The ability to switch from global to local processing in faces will thus depend on whether the appropriate representation in long-term storage has been activated.

In the pictorial data store there must be some representation of the spatial properties of a face. Such a representation, however general, will allow for rapid decision as to whether a stimulus is a face or a nonface (Hay, 1981) and presumably is involved in the faster recognition of a face than of a spatial rearrangement of a face (Homa et al., 1976). It is therefore possible to use the superior

This work was supported by Medical Research Council Grant G $973 / 144$ and an ESF twinning grant. Thanks are extended to A. Sykes for statistical advice.

The author's present address is: Department of Psychology. University College of Swansea, Singleton Park, Swansea SA2 8PP, U.K. recognition of faces over scrambled faces as an indicator that the description in the pictorial data store has been accessed. The conditions under which the face superiority disappears will then be particularly important in determining the nature of the face representation.

The first three experiments of the present paper varied the identity of the elements that constitute a face and altered their spatial characteristics. The experiments to be reported in the present paper used schematic faces in the interest of stimulus control. It is clear that, although to some extent artificial, they do act like faces, even to the extent of causing face-specific neurons to fire in the monkey cortex (Perrett, Roles, \& Caan, 1982). The last two experiments were concerned with the relationship between exposure duration and the face superiority effect.

The effect of stimulus duration has been insufficiently investigated, but it is clear that the meaning of a picture is apparent from even very briefly presented stimuli (Biederman, 1972). It would appear that existing descriptions or schema are accessed quickly and then followed by an analysis of details (Friedman, 1979; Loftus et al., 1983). In their study Loftus et al. (1983) found that, with a 250-msec exposure, holistic information was more reliably retained than was detail, but that, with a $500-\mathrm{msec}$ exposure, the reverse was true. Consistent with these findings, Smith and Nielsen (1970) showed that stimulus duration alters strategies used for face recognition. Since long exposures will allow extraction of details from both faces and nonfaces, it should follow that any facilitation in feature recognition provided by faces should be affected by exposure duration. In Experiments 4 and 5, therefore, stimulus duration was altered with the expectation that face superiority effects would occur only for short exposure durations.

\section{EXPERIMENT 1}

It is highly likely that the description of a face held in the pictorial data store is defined spatially. The first ex- 
periment therefore considered the role of spatial relationships between facial features in producing face superiority effects. Each feature of a face description also has limits; that is, not every stimulus will be acceptable as a facial feature, although, in fact, a wide variety are (Palmer, 1975). The present experiment investigated the recognition of a facial feature when placed in the correct or incorrect spatial position with respect to a face surround and when accompanied by features that obviously went beyond the limit of acceptability as facial features. The methodology used was similar to that used by Homa et al. (1976, Experiment 1), except that the displays had only one facial feature in the three-feature display. An example of the type of stimulus (which will be called a onefeature face) is given in Figure 1a. The main question asked was whether, in recognition, one-feature faces would provide superior retention of the facial feature than would Figure $1 \mathrm{~b}$ (scrambled one-feature faces) displays. For example, in the case illustrated (Figure 1a vs. Figure $1 \mathrm{~b}$ ), would the eyes be better recognized from the one-feature face or from the scrambled version?

\section{Method}

Subjects. Eight paid volunteers, aged 19-40 years, from the Neuropsychology Unit's subject panel participated in this experiment.

Materials. The features used in this experiment can be seen in Figure 2. The eyes, noses, and mouths were redrawn from Homa et al. (1976). The cars, leaves, and telephones were obtained from Letraset. Homa et al. (1976) have shown that when facial features are presented singly in the correct position with respect to the face surround, the features are equally easy to recognize, but this was nevertheless replicated in a pilot study for a $125-\mathrm{msec}$ exposure. A similar exercise was carried out for the cars, leaves, and telephones, which provided recognition levels not significantly different from each other or from those for the facial features.

A facial feature from Figure 2 was combined with two other nonfacial features. For the eyes, the accompanying feanures were leaves
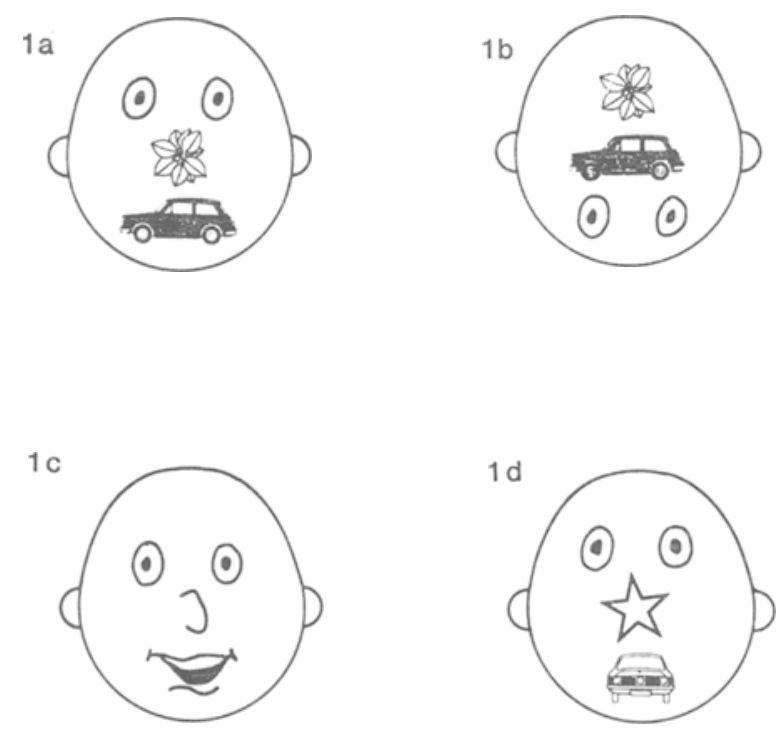

Figure 1. Examples of the stimuli used in Experiment 1 (1a vs. 1b), Experiment 3 (1a vs. 1c), and Experiment 4 (1c vs. 1d).

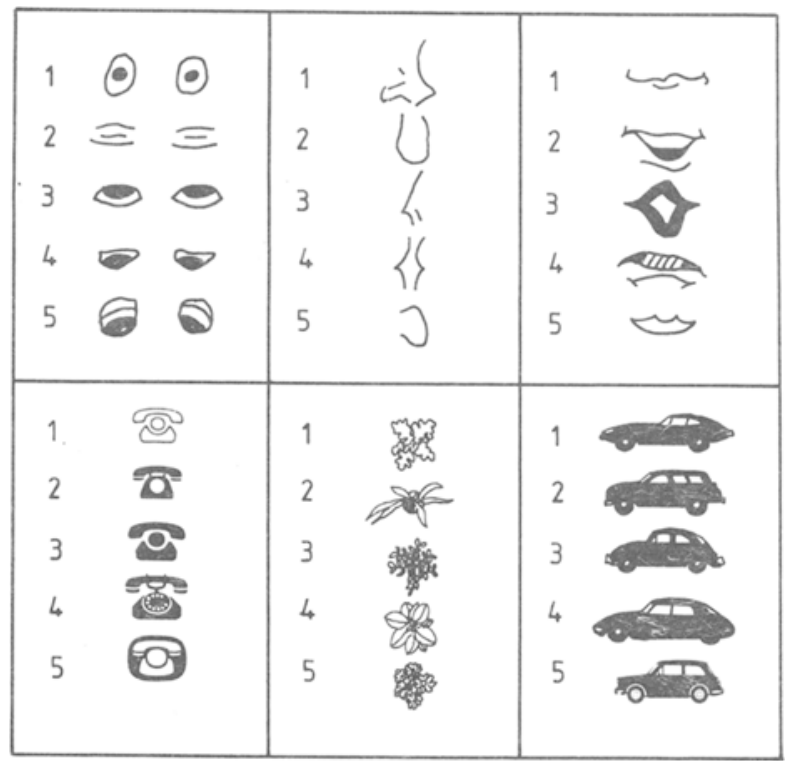

Figure 2. Alternative facial and nonfacial features for Experiments 1,2 , and 3 .

and cars; for the noses, they were telephones and cars; and for the mouths, they were telephones and leaves. For the one-feature faces, the facial feature was in the correct spatial position. The nonfacial features were always presented in the same spatial location: telephone at the top, leaves in the middle, and car at the bottom. For the scrambled one-feature faces, the two nonfacial features were always in the same spatial location: leaves at the top, car in the middle, and telephone at the bottom. The facial feature was always in the wrong position; nose at the top, mouth in the center, and eyes at the bottom.

Thirty different one-feature faces were constructed. Each of the five alternatives for the three facial features was used twice, and the nonfacial features were used equally often. These 30 combinations of facial and nonfacial features were each rearranged to form a scrambled version. The oval face surround subtended approximately $4^{\circ}$ when presented in an Electronic Developments threefield tachistoscope at a luminance of $2.7 \mathrm{~lx}$.

Procedure. A brief display, either a one-feature face or a scrambled nonface, appeared $1 \mathrm{sec}$ after a warning signal (a flash of light). Display time was $500 \mathrm{msec}$, which was found to give roughly $60 \%$ accuracy. ${ }^{1}$ The brief display was followed immediately by a recognition test for one of the features of the display. The five alternatives for the forced-choice recognition were presented for $10 \mathrm{sec}$ to the right of a patterned visual mask ${ }^{2}$ superimposed over the display, by using another field of the tachistoscope. The subject chose one of the alternatives without time pressure. There was a 5-sec interval before the next warning signal and subsequent display. Each feature acted equally often as the target, and the subjects were advised against guessing which of the three features would have to be recognized.

Testing lasted approximately $45 \mathrm{~min}$ and included an opportunity to inspect the stimuli before the practice trials. The 10 practice trials were followed by the 120 test trials with each of the 60 displays being tested for the recognition of a facial and a nonfacial feature. Order of presentation of the stimuli was randomized, with the order being changed after 4 subjects had been run.

\section{Results}

The recognition scores were analyzed for facial and nonfacial targets from both one-feature faces and scram- 
Table 1

Mean Percentage Recognition Scores for Facial and Nonfacial Features for Displays Using One-Feature and Scrambled One-Feature Faces

\begin{tabular}{lccccccc}
\hline & \multicolumn{3}{c}{ Facial Feature } & & \multicolumn{3}{c}{ Nonfacial Feature } \\
\cline { 2 - 3 } \cline { 7 - 8 } & Eyes & Nose & Mouth & & Telephone & Leaves & Car \\
\hline $\begin{array}{l}\text { One-Feature Face } \\
\text { (Figure 1a) }\end{array}$ & 80.0 & 80.0 & 75.0 & & 57.5 & 55.0 & 61.3 \\
Scrambled One-Feature Face & 63.8 & 61.3 & 67.5 & & 53.8 & 61.3 & 61.3 \\
(Figure 1b) & (bottom) & (top) & (middle) & (bottom) & (top) & (middle) \\
\hline
\end{tabular}

Note-"Top," "middle," and "bottom" refer to positions in face surround.

bled versions. Table 1 shows the mean recognition scores. A two-way analysis of variance (feature $x$ position) for the facial feature targets revealed that they were recognized better if they were in the correct facial position $[F(1,38)=10.39, p<.01]$. There was no difference in recognition performance between the types of facial feature $[F(2,38)<1]$, and the interaction was not significant $[F(2,38)<1]$. A two-way analysis of variance for the nonfacial targets (feature $x$ position) revealed no significant effects (all $F_{\mathrm{S}}<1$ ).

\section{Discussion}

The correct positioning of a facial feature in a face allows better recognition of that feature even when it is presented with nonfacial features. The nonfacial targets did not behave in the same fashion; recognition was not dependent on position in the face surround. Correct spatial position of a facial feature is therefore part of what constitutes the description of a face in the pictorial data store. We now ask whether it is sufficient to produce a face superiority effect without other surrounding features. The next experiment investigated this issue to determine whether a feature alone was better recognized when that feature was in the correct position with respect to the facial surround.

\section{EXPERIMENT 2}

\section{Method}

Subjects. Eight different subjects, aged 18-30 years, were paid to participate in this experiment.

Materials and Procedure. The displays used were as in Experiment 1 , except that only the facial feature was present in the stimulus; that is, the displays were one-feature faces and scrambled onefeature faces with the nonfacial features removed. The procedure was similar to that of Experiment 1, except that there were only 30 trials with the feature in the correct position and 30 with it in the incorrect position. To prevent ceiling effects, display presentation was for $125 \mathrm{msec}$.

\section{Results}

A two-way analysis of variance (facial feature $x$ correct vs. incorrect position) of the recognition scores (Table 2) showed that recognition did not differ on the basis of the position of the facial feature $[F(1,35)=1.31$, $p>.2]$. Overall, the features were equally well recognized $[F(2,35)<1]$, but the interaction was significant $[F(2,35)=15.2, p<.001]$. The facial feature in the central position was best recognized in both types of displays.

\section{Discussion}

Recognition is not better for a single facial feature when it is in the correct as opposed to the incorrect spatial position within the schematic facial surround. Inspection of Table 2 shows that there is superior recognition for a feature placed at fixation (center of the face) irrespective of whether it is appropriate for that position. It would appear that when the recognition task does not allow for the use of spatial relationships between internal facial features, a different strategy is employed for recognition. It would seem reasonable to believe that an attempt is made to get as much detail as possible into short-term storage for matching to the probe stimulus.

Homa et al. (1976) found that facial features were not equally well recognized from displays (which will be called normal faces) like that shown as Figure 1c. They found that the nose features were recognized poorly despite the fact that this was not true when they were presented in isolation. Since Experiment 1 did not find poor recognition of nose features in one-feature faces, such displays must be dealt with differently from the normal faces of Homa et al. (1976). It is suggested that onefeature faces gain some advantage from their closeness to the description of a face in the pictoral data store, but that the strategy for feature selection nevertheless differs from that for normal faces. The next experiment further examined this possibility by comparing recognition of normal and one-feature faces.

Table 2

Mean Percentage Recognition Scores for Facial Features when Presented Alone (Without Nonfacial Features) in the Correct or Incorrect Position

\begin{tabular}{|c|c|c|c|c|c|}
\hline \multicolumn{3}{|c|}{$\begin{array}{l}\text { Facial Feature in Correct Position } \\
\text { (Figure 1a) }\end{array}$} & \multicolumn{3}{|c|}{$\begin{array}{l}\text { Facial Feature Not in Correct Position } \\
\text { (Figure lb) }\end{array}$} \\
\hline Eyes & Nose & Mouth & Eyes & Nose & Mouth \\
\hline $\begin{array}{l}72.5 \\
\text { (top) }\end{array}$ & $\begin{array}{c}85.0 \\
\text { (middle) }\end{array}$ & $\begin{array}{c}70.0 \\
\text { (bottom) }\end{array}$ & $\begin{array}{c}72.5 \\
\text { (bottom) }\end{array}$ & $\begin{array}{l}63.8 \\
\text { (top) }\end{array}$ & $\begin{array}{c}82.5 \\
\text { (middle) }\end{array}$ \\
\hline
\end{tabular}




\section{EXPERIMENT 3}

The results of Experiment 1 argue for recognition impairments for one-feature faces when the normal spatial location of the facial feature is changed. But what happens if spatial location is kept constant? Does recognition performance for a facial feature depend on the resemblance of the other features to those normally found in faces? If so, there should be an advantage for recognition of, say, eyes in normal faces over those in one-feature faces.

\section{Method}

Subjects. Thirty different subjects, aged $18-30$ years, were paid to participate in this experiment.

Materials and Procedure. Displays of normal faces were constructed by taking the one-feature faces from Experiment 1 and replacing the nonfacial features with an appropriately positioned facial feature chosen from those used by Homa et al. (see Figure 2). All features were used equally often.

The procedure was much the same as that of Experiment 1 except that 90 test trials were run. These consisted of 30 trials using normal-face displays and $\mathbf{6 0}$ using one-feature faces. The latter displays had 30 facial and 30 nonfacial features tested for recognition. Each facial feature occurred equally often in the one-feature faces. Fifteen subjects were run with one random order and 15 were run with another. The displays were exposed for $350 \mathrm{msec}$.

\section{Results}

The correct recognition scores for the facial features were subjected to a two-way analysis of variance (facial feature $x$ context: normal faces vs, one-feature faces), which revealed that facial features were better recognized in a face context than when accompanied by nonfacial features $[F(1,58)=22.83, p<.001]$. There was a difference (see Table 3) between the recognition scores for the three types of facial feature $[F(2,58)=12.95, p<.001]$, and this interacted with context $[F(2,58)=9.07$, $p<.001]$. Analysis of this interaction shows that eyes are better recognized when in the context of a face $[t(29)$ $=6.92, p<.001]$; the same is true for mouths [ $t(29)$ $=2.36, p<.05]$ but not for noses $(t<1)$. It also shows that there is no difference in recognition among the three facial features when they are accompanied by nonfacial features $[F(2,58)=1.95, p>.1]$.

\section{Discussion}

Normal faces make it easier to recognize facial features. It is argued that this face superiority effect depends on the description of a face held in the pictorial data store

Table 3

The Effect of Context: Mean Percentage Recognition Scores for Facial Features When Presented in Displays Like Figure 1a (One-Feature Faces) and Figure 1c (Normal Faces)

\begin{tabular}{lccccccc}
\hline & \multicolumn{3}{c}{ Facial Feature } & & \multicolumn{3}{c}{ Nonfacial Feature } \\
\cline { 2 - 3 } & Eyes & Nose & Mouth & & Telephone & Leaves & Car \\
\hline Normal Faces & 81.3 & 47.7 & 61.3 & & & \\
$\begin{array}{lllllll}\text { One-Feature } \\
\text { Faces }\end{array}$ & 56.7 & 46.0 & 51.3 & & 54.0 & 58.7 & 45.0 \\
(top) & (middle) & (bottom) \\
\hline
\end{tabular}

and that it has implications for the particular features that are best recognized. For normal faces, eye and mouth features are both better recognized than nose features, with the eyes recognized best. Homa et al. (1976) also noted the change in relative performance levels between the features when recognition of face displays was compared with that of isolated features, but, except to point out that it could not be due to top-to-bottom scanning as Smith and Nielsen (1970) had proposed, they gave no explanation for this.

If a stimulus is first classified as a face, then it will be the resemblance to the description of the face that is important in determining which facial feature is best recognized. Only the correct resemblance will initiate the normal strategies for feature inspection. One-feature faces do not have a close resemblance, and for them (both in this experiment and in Experiment 1) eyes are not significantly better recognized than the other facial features.

The comparison made between face superiority effects for normal faces and those for one-feature faces is valid only if the subject does not make a decision to attend selectively to facial or nonfacial features in one-feature faces. Selective attention to nonfacial features in one-feature faces could cause poorer recognition of facial features and so invalidate a comparison made with normal faces. Since this experiment does, indeed, show evidence for reduced recognition performance if the facial features are replaced by nonfacial features, it is important to consider the issue of selective attention.

To assess properly the recognition superiority of facial features from normal faces over those from one-feature faces, the comparison needs to be made when, for onefeature faces, performance on the nonfacial features is equal to that on the facial features. We can obtain this equal-performance point from the group data by using a regression equation. We can plot, for each subject, the effect of "faceness," that is, the difference between recognition of features in normal faces and recognition of those in one-feature faces $(y)$ against the difference between recognition of facial and nonfacial features in onefeature faces $(x)$. We need the value of the intercept of the regression equation when $x=0$. At this point, recognition of facial and nonfacial features in one-feature faces is equal. If the intercept is significantly different from zero (Armitage, 1971, p. 160), then there is true superiority for the recognition of facial features from normal faces over that from one-feature faces. Figure 3 shows the data from Experiment 3 plotted in this fashion and the regression line $(y=-4.77 x+3.66)$ obtained. When $x=0$, $y$ (the intercept) $=3.66$, a value significantly different from zero $[t(28)=6.54, p<.001]$. The robust nature of the face superiority effect for normal faces is evident in Figure 3. It is only for the most extreme cases of selective attention to the facial feature in the one-feature faces that the advantage of the face context does not occur.

The advantage of the regression method in assessing whether normal faces produce superior feature recognition to one-feature faces is that subjects do not necessar- 


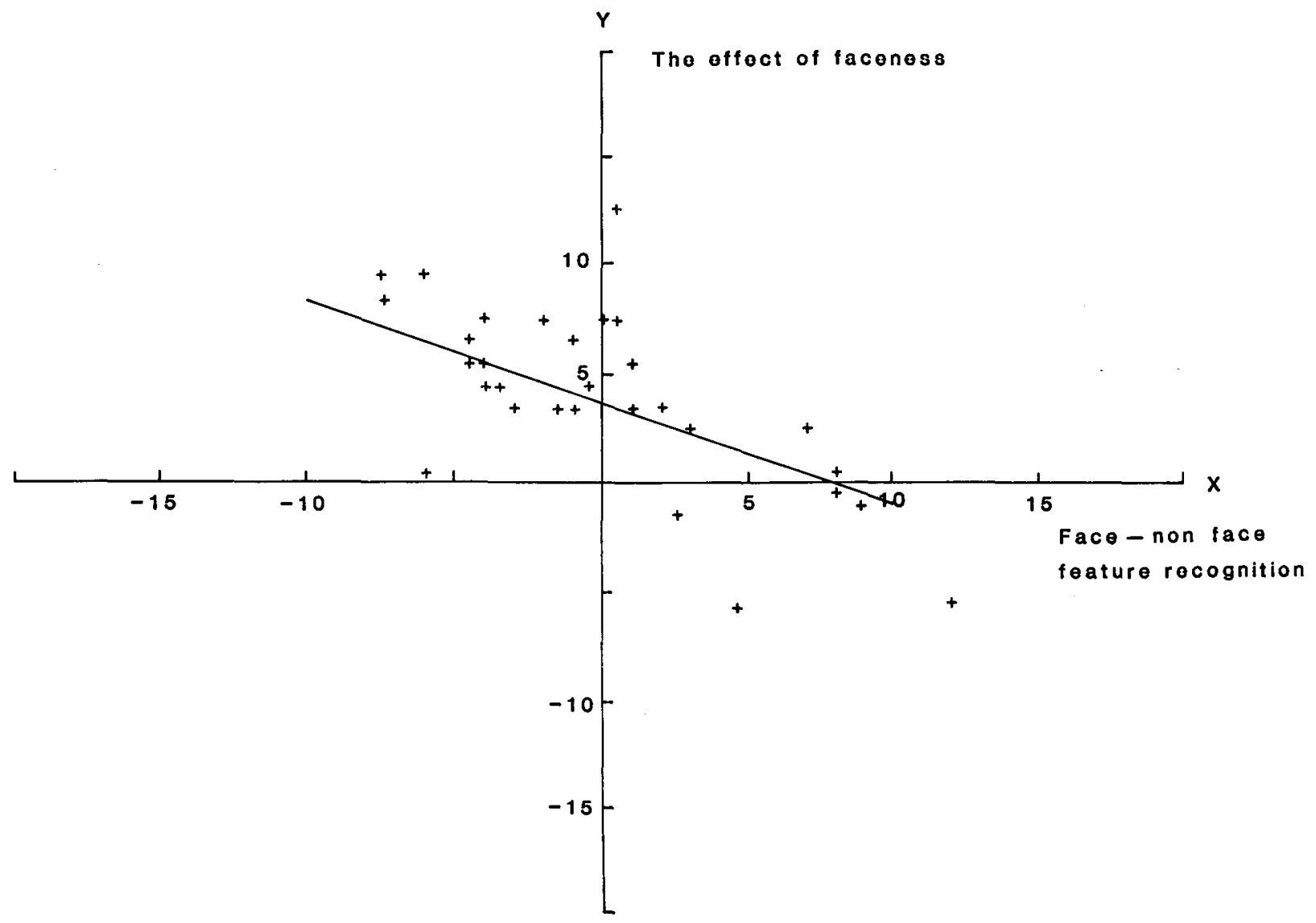

Figure 3. The use of a regression analysis to determine the effect of "faceness" in Experiment 3.

ily have to attend equally to facial or nonfacial features; they can choose to extract information as they wish. In the present study, this is useful because there are differences in the proportion of facial to nonfacial features recognized from one-feature faces that would seem to be related to exposure time. For Experiment 3, marginally more subjects recognized nonfacial features better (see Figure 3), whereas, at a 500-msec exposure (Experiment 1 ), they recognized facial features better.

The above analysis rests on the assumption that equal attention to facial and nonfacial features can be assumed when $x=0$. This would seem to be a reasonable assumption, but it could be disputed. It could be argued that despite the attempt to equate discriminability between facial and nonfacial features at $125 \mathrm{msec}$, at the exposure durations used the facial features become easier to recognize. But we have seen that the shorter the exposure duration ( 350 vs. $500 \mathrm{msec}$ ), the more likely it is that nonfacial features will be reported, which does not suggest that the facial features have become easier to discriminate. It could be further argued that, even if discriminations between isolated versions of the two types of feature are the same, when presented as part of one-feature faces the nonfacial features are at a disadvantage because there are two of them and more attentional capacity is required to produce equal recognition performance. However, this does seem unlikely to be a sufficient explanation of the face superiority effect, since it is only in extreme cases of selective attention to facial over nonfacial features that a facial superiority effect is not observed. The estimation of the intercept value by a linear regression might also be contested, but as there are no a priori grounds for assuming any relationship to be curvilinear, parsimony would suggest using the simplest approach.

The regression analysis allows an assessment of a face superiority effect for any display that contains a facial feature. It would also be possible to vary the individual facial features to find the limits to their being facelike, that is, when they stopped contributing to a face superiority effect (presumably because they no longer conformed to the description of a face held in the pictorial data store). The technique may also have more general applications. Consider, for example, the task of learning items that are embedded in either similar or different material. Any advantage found for the similar context would be open to alternative interpretations if differential attention was 
paid to the two types of material. The regression analysis could estimate performance at the point of equal attention even if this were not achieved.

\section{EXPERIMENT 4}

Diamond and Carey (1977) showed that young children do not recognize unfamiliar faces by taking account of the relationships among the internal features of a face. Rather, their responses are dominated by individual (often nonfacial) features. Similar effects may be observed in brain-damaged populations, which Davidoff (1984) has attributed to an inability on the part of such patients to process rapidly presented information, making it hard for them to effectively use the face description in the pictorial data store. Experiment 4 investigated the effect of exposure duration on the face superiority effect, using probed recognition for facial features. The experiment also served to ensure that the regression equation procedure demonstrated in Experiment 3 could be applied to other features. A new set of one-feature faces (an example is given as Figure 1d) was compiled and presented with normal faces at three exposure times. The major consideration underlying the choice of stimulus duration was the need to contrast an exposure at which a face superiority effect was known to occur ( $350 \mathrm{msec}$ ) with one of a much longer duration $(1 \mathrm{sec})$. A smaller number of subjects were run at $750 \mathrm{msec}$ in a pilot study, and these results are included in the analyses.

\section{Method}

Subjects. A total of 74 unpaid subjects, aged 18-30 years, participated in this experiment. They were divided into three groups according to availability.

Materials and Procedure. There was no theoretical reason for the choices of the nonfacial features in the previous experiments. To determine whether or not the results obtained were peculiar to those items, the nonfacial features were altered. The telephones were replaced by arrows, the leaves were replaced by stars, and a different set of cars was used. Figure 4 shows the five alternatives used for these new nonfacial features. The facial features were as in the previous experiments.

The procedure was the same as that used in Experiment 3, except that there were three groups of subjects. Each subject was tested at only one of the three exposure times $(350,750$, or $1,000 \mathrm{msec})$. Twenty-four subjects were run at $350 \mathrm{msec}, 16$ were run at $750 \mathrm{msec}$, and 34 were run at $1,000 \mathrm{msec}$.

\section{Results}

A one-way analysis of variance on the overall performance scores showed that exposure time was a significant factor $[F(2,69)=46.30, p<.001]$. This was due to the low performance obtained at $350 \mathrm{msec}(55.0 \%$ accuracy); performance at $750 \mathrm{msec}(69.5 \%)$ did not differ from that at $1 \mathrm{sec}(72.8 \%)[t(48)=1.50, p>.1$; see Table 4].

The effect of exposure time was considered separately for normal faces and for the facial and nonfacial features of the one-feature faces. For normal faces, the two-way analysis of variance (feature $\times$ exposure time) showed

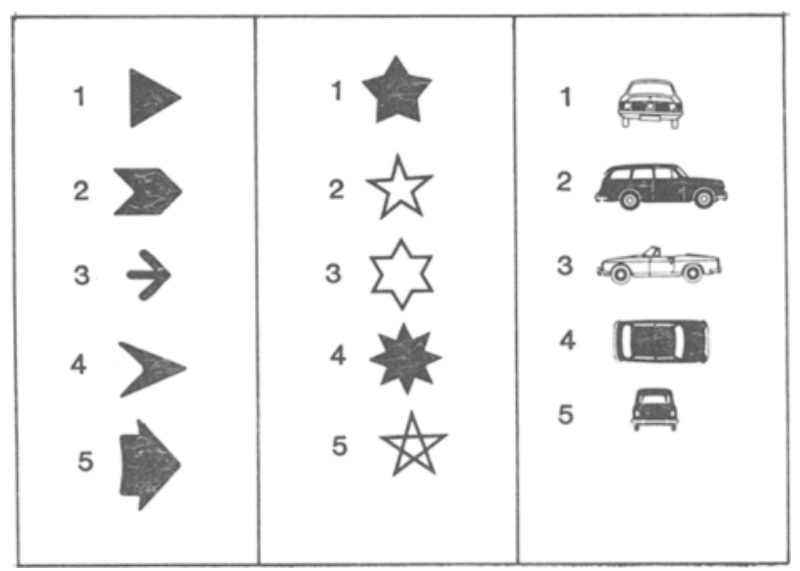

Figure 4. Alternative nonfacial features for Experiment 4.

significant effects for exposure time $[F(2,71)=21.80$, $p<.01]$, feature type $[F(2,142)=8.57, p<.01]$, and the interaction $[F(4,142)=4.68, p<.01]$. A breakdown of the interaction revealed that feature recognition differed only at $350 \mathrm{msec}$. The nose feature was recognized less well than the eyes $[(t(142)=5.08, p<.01]$ and the mouth $[t(142)=3.86, p<.01]$. Pairwise comparisons for the effect of exposure time showed significant differences only for the nose and mouth features. Performance at $350 \mathrm{msec}$ differed from that at 750 and $1,000 \mathrm{msec}$ (all all $t$ values give $\mathrm{p}<.05$ ).

Considering the facial features of the one-feature faces, the analysis of variance (feature $\times$ exposure time) showed a significant effect of exposure time $[F(2,71)=43.25$, $p<.01]$ and a significant interaction $[F(4,142)=2.57$, $p<.05]$. The interaction revealed a difference between the features recognized at $750 \mathrm{msec}$; this was not the case for the other two exposure durations. At $750 \mathrm{msec}$, the eyes were better recognized than the nose $[t(142)=2.84$, $p<.01]$ or the mouth $[t(142)=2.27, p<.05]$. The effect of increasing exposure time was to improve performance between 350 and $750 \mathrm{msec}$ but not between 750 and $1,000 \mathrm{msec}$. The only exception to this was the nose feature, which differed only between the 350- and 1,000msec exposures (all $t$ values give $\mathrm{p}<.01$ ).

Table 4

Mean Percentage Recognition Scores for Facial and Nonfacial Features for Experiment 4

\begin{tabular}{ccccccc}
\hline & & & \multicolumn{3}{c}{ Exposure Duration (Milliseconds) } \\
\cline { 5 - 6 } Face & Position & Feature & 350 & 750 & 1,000 \\
\hline Normal & top & Eyes & 70.0 & 70.0 & 72.6 \\
& middle & Nose & 44.2 & 71.3 & 71.2 \\
& bottom & Mouth & 63.8 & 75.0 & 80.6 \\
& top & Eyes & 50.4 & 81.9 & 76.8 \\
& middle & Nose & 55.8 & 66.2 & 79.6 \\
& bottom & Mouth & 47.1 & 69.4 & 75.9 \\
One-Feature & top & Arrow & 45.0 & 64.4 & 67.1 \\
& middle & Stars & 70.8 & 60.0 & 67.4 \\
& bottom & Cars & 48.3 & 67.5 & 66.5 \\
\hline
\end{tabular}


Recognition of the nonfacial features was analyzed by a separate analysis of variance (feature $x$ exposure time). The effect of exposure time was significant $[F(2,71)=$ $13.21, p<.01]$, as were the differences between the features $[F(2,142)=3.78, p<.05]$ and the interaction $[F(142)=6.10, p<.01]$. At $350 \mathrm{msec}$, the middle (star) feature was better recognized than either the arrows $[t(142)=4.26, p<.01]$ or the cars $[t(142)=4.12$, $p<.01]$. There were no differences in feature recognition at the other two exposure times. The effect of exposure time was to improve recognition of the arrows and cars. Performances at $350 \mathrm{msec}$ differed from that at both 750 and $1,000 \mathrm{msec}$ (all $t$ values give $\mathrm{p}<.01$ ).

Figure 5 shows the regression lines $(y=-.63 x+1.66$; $y=.44 x+1.22 ; y=-.44 x+0.56)$ for the three groups calculated in the same fashion as for Experiment 3. Only the shortest exposure time $(350 \mathrm{msec})$ resulted in a significant intercept $[x=0, y=1.66 ; t(22)=2.51$, $p<.02]$; exposure times of $750 \mathrm{msec}[x=0, y=1.22$; $t(14)=1.77, p>.2]$ and $1 \sec [x=0, y=0.56$, $t<1]$ did not.

\section{Discussion}

The principal finding of Experiment 4 is that a face superiority effect occurred only for the shortest $(350 \mathrm{msec})$ exposure time. The conclusion would be less certain without the use of the regression analysis, because exposure time may differentially affect the features that are recognized. A comparison of the results of Experiment 1 with those of Experiment 3 does show that better performance is found for facial features than for nonfacial features as longer time is given to inspection of the displays, which could well be due to an attentional preference. However, the use of the regression analysis in the present experiment refutes any argument that it is any attentional preference for the facial features (at 750 and $1,000 \mathrm{msec}$ ) that has removed the face superiority effect.

The action of the face description held in the pictorial data store is evident when recognition performance for the middle feature from the different types of display at the shortest $(350 \mathrm{msec})$ exposure duration is considered. For nonfacial features of one-feature faces, the item at fixation is the one that is best recognized, a finding that is similar to that of Experiment 2. In that experiment, in which features were presented in isolation, recognition of both facial and nonfacial features were better at fixation. We may reasonably assume that this recognition does not involve the face description in the pictorial data store. However, for normal faces, the pictorial data store is accessed. The rapid face classification (providing face su-

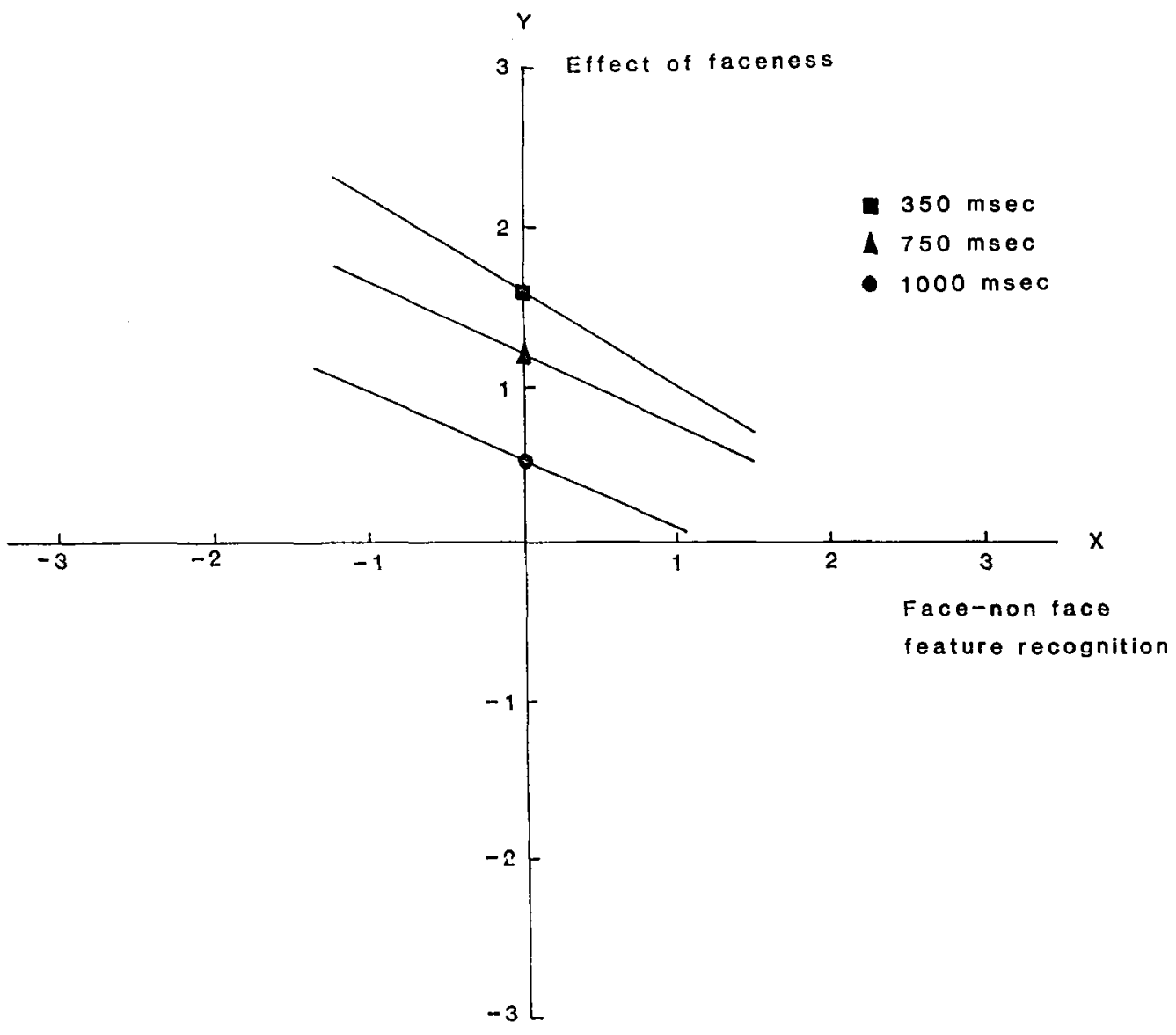

Figure 5. The role of exposure time in the superior recognition of faces (Experiment 4). 
periority effects) initiates a feature selection that does not favor the middle (nose) feature. Recognition of the middle face feature (mouth) in one-feature faces falls somewhere in between, there being no difference in recognition between any of the facial features.

The present experiment revealed no face superiority effect for the recognition of facial features when exposure duration was lengthened. The next experiment extended the generality of this finding.

\section{EXPERIMENT 5}

If long exposure durations encourage recognition of individual features, then it could well follow that the face superiority effect reported by Homa et al. (1976) would disappear if the exposure duration was increased. A replication of part of their study was carried out, maintaining all important conditions except for exposure time. Since only facial features were used, the question of division of attention between facial and nonfacial features does not arise.

\section{Method \\ Subjects. Eight paid student volunteers from University College Swansea participated in this experiment. \\ Materials and Procedure. The features used were the eyes, noses, and mouths redrawn from Homa et al. (see Figure 2). The 30 normal faces from Experiments 3 and 4 were used, plus 30 scram- bled variations of these faces as in Homa et al. (1976). The scram- bled faces had the nose placed at the top of the face, the mouth in the middle, and the eyes in the bottom position.}

\section{Results}

A two-way analysis of variance (face feature $\times$ normal vs. scrambled face) produced no significant effects (see Table 5). The only $F$ ratio greater than 1 was for feature recognition $[F(2,35)=1.41]$, which did not approach significance.

\section{Discussion}

Extending exposure duration to $1 \mathrm{sec}$ removed any trace of a face superiority effect when probed recognition was used as in Homa et al. (1976). Since it is clear that this is not due to a ceiling effect, because performance was still far from perfect, it must, rather, have arisen from changes in the procedures used to effect recognition.

Table 5

Mean Percentage Recognition Scores for Facial Features from Normal and Scrambled Faces

\begin{tabular}{lccc}
\hline & \multicolumn{3}{c}{ Feature } \\
\cline { 2 - 4 } & Eyes & Nose & Mouth \\
\hline Normal Face & 70.0 & 75.0 & 81.3 \\
& (top) & (middle) & (bottom) \\
Scrambled Face & 72.5 & 68.8 & 76.3 \\
& (bottom) & (top) & (middle)
\end{tabular}

Note-"Top," "middle," and "bottom" refer to positions in face surround.

\section{GENERAL DISCUSSION}

The proposal that we can rapidly extract the gist of a scene (Loftus et al., 1983) suggests an encoding advantage for meaningful displays. Encoding has also been given (Bell \& Handel, 1976) as the locus of the advantage found for the reproduction of "good" patterns. However, Howe and Brandau (1983) have shown that effects of pattern goodness also depend on maintenance rehearsal, and are therefore in part due to differential shortterm forgetting. Preferential maintenance in short-term memory was also proposed by Seymour (1979) for the word superiority effect, although others (McClelland \& Rumelhart, 1981; Rumelhart \& McClelland, 1982; Paap, Newsome, McDonald, \& Schvaneveldt, 1982) have suggested that word over nonword advantages depend on other combinations of data-driven and top-down processing. The processing of faces appears to have some similarity to that for both patterns and words.

There is a surface similarity between word and face recognition in that, for both, whole versus part recognition is affected by exposure duration. However, they are affected in different ways. Massaro and Klitzke (1979) have shown that exposure duration is an important determinant of whether letters or words are better recognized. The advantage for words over letters at short exposure durations is due to the differential effects of exposure duration on lateral masking and the use of orthographic structure. At long exposure durations, lateral masking effects are reduced. For faces, increasing exposure duration does not reduce the advantage for the meaningful displays by eliminating lateral masking but by allowing feature identification strategies to operate. Strategies for part (letter) selection also occur for words, but these are more important developmentally (Davidoff, Beaton, Done, \& Booth, 1982).

Faces are clearly unlike words in that they can be recognized without reference to the identity of the stimulus. Quite unrealistic caricature faces, such as those used in the present studies, are nevertheless recognizable as faces and exhibit face superiority effects. Therefore, in line with Ellis's (1983) model, it is suggested that the classification of a stimulus as a face needs to be distinguished from the identification of a particular face. A recent model of face recognition (Hay \& Young, 1982) proposes that units similar to lexical recognition units (Morton, 1969) have the function of receiving visual information relevant to the recognition of an individual. These units are the first processing stage at which top-down effects operate. However, we also need a mechanism by which a stimulus can be categorized as a face. Since classification allows a search for face parts to be initiated, top-down effects can be seen to be operating before the stage of individual recognition. The strategy norm for extraction of facial features appears to be a concentration on the eyes (Haig, 1984; Walker-Smith, 1978). 
A duality of available processing mechanisms in normal face recognition has been previously noted. Smith and Nielsen (1970) found that facial features were processed in parallel (holistic processing) if the delay between presentation and test was short. However, at $4 \mathrm{sec}$ delay, a serial search was suggested, since recognition latency was determined by the number of features that constituted their schematic faces. The improvement in recognition, which was seen in the present experiments with increasing exposure times, was presumably a result of the benefit this gives to feature-by-feature inspection. The improvement obtained with long exposures is, in fact, fairly small, as noted previously by Mooney (1960), but it is nevertheless significant.

Feature matching may be an automatically applied strategy or it could represent a decision on the part of the subject. If the latter is the case, under some circumstances, a face superiority effect could be obtained for longer exposures than the maximum found here. In line with this suggestion, Nielsen and Smith (1973) report that giving subjects instructions to image extended holistic processing beyond the 4-sec delay found in Smith and Nielsen (1970). Practice may also alter the exposure duration for which face superiority effects are found, since practice enhances the effect (Homa et al., 1976) and changes processing strategies (Schneider \& Shiffrin, 1977; Spelke, Hirst, \& Neisser, 1976).

In summary, this paper represents an attempt to understand more about the mental representation of a face as used for face classification. The spatial relationship between the internal features and the nature of the features is found to be critical, although the limiting values are yet to be determined. It is likely that the description of a face (held in some pictorial data store) is of a general type. Atypical faces (with respect to the spatial relationships between features) or those with distinctive features would be recognized differently from typical faces. Distinctive faces offer better delayed recognition than typical faces (Light, Kayra-Stuart, \& Hollander, 1979), and in the present model this could be explained by the preferred storage of the results of a feature-matching strategy. Also, extremely atypical faces should show less of a face superiority effect, since they would not conform as well to the general description of a face.

\section{REFERENCES}

ARmitage, P. (1971). Statistical methods in medical research. Oxford: Blackwell Scientific Publication.

BeLL, H. H. \& HANDEL, S. (1976). The role of pattern goodness in the reproduction of backward masked patterns. Journal of Experimental Psychology: Human Perception \& Performance, 2, 139-150.

Biederman, I. (1972). Perceiving real world scenes. Science, 177. $77-80$.

BREITMEYER, B. G. (1984). Visual masking: An integrative approach. Oxford: Clarendon Press.

Checkosky, S. F., \& Whitlock, D. (1973). The effects of pattern goodness on recognition time in memory search task. Journal of Experimental Psychology, 100, 341-348.
Davidoff, J. B. (1984). Precategorical perception and cognition. Cognitive Neuropsychology, 1, 159-162.

Davidoff, J. B., Beaton, A. A., Done, D. J., \& Booth, H. (1982), Information extraction from brief verbal displays: Half-field and serial position effects for children, normal and illiterate adults. British Joumal of Psychology, 73, 29-39.

DiAmond, R., \& CAREY, S. (1977). Developmental changes in the representation of faces. Journal of Experimental Child Psychology, 23, 1-22.

ELLIS, H. D. (1983). The role of the right hemisphere in face perception. In A. W. Young (Ed.), Functions of the right hemisphere. London: Academic Press.

FriEDMAN, A. (1979). Framing pictures: The role of knowledge in automized encoding and memory for gist. Journal of Experimental Psychology: General, 108, 316-355.

FRYKLUND, I. (1975). Effects of cued-set spatial arrangement and target background similarity in the partial report paradigm. Perception \& Psychophysics, 17, 375-386.

HAIG, N. D. (1984). The effect of feature displacement on face recognition. Perception, 13, 502-512.

HAY, D. C. (1981). Asymmetries in face processing: Evidence for a right hemisphere perceptual advantage. Quarterly Journal of Experimental Psychology, 33A, 267-274.

HAY, D. C., \& Young, A. W. (1982). The human face. In A. W. Ellis (Ed.), Normality and pathology in cognitive functions. London: Academic Press.

Homa, D., Haver, B., \& Schwartz, T. (1976). Perceptibility of schematic face stimuli: Evidence for a perceptual Gestalt. Memory \& Cognition, 4, 175-185.

Howe, E. S., \& Brandau, C. J. (1983). The temporal course of visual pattern encoding: Effects of pattern goodness. Quarterly Journal of Experimental Psychology, 35A, 607-633.

KoffKA, K. (1935). Principles of Gestalt psychology. London: Routledge \& Kegan Paul.

Light, L., Kayra-Stuart, F., \& Hollander, S. (1979). Recognition memory for typical and unusual faces. Journal of Experimental Psychology: Human Learning \& Memory, 5, 221-228.

Loftus, G. R., Neison, W. W., \& Kallman, J. J. (1983). Differential acquisition rates for different types of information from pictures. Quarterly Joumal of Experimental Psychology, 35A, 187-198.

Massaro, D. W., \& KuITZKE, D. (1979). The role of lateral masking and orthographic structure in letter and word recognition. Acta Psychologica, 43, 413-426.

McClelland, J. L., \& RumelmaRT, D. E. (1981). An interactive activation model of context effects in letter perception: Part 1. An account of basic findings. Psychological Review, 88, 375-407.

Mollon, J. D., \& Polden, P. G. (1978). On the time constants of tachistoscopes. Quarterly Journal of Experimental Psychology, 30, 555-568.

MOONEY, C. M. (1960). Recognition of ambiguous and unambiguous visual configurations with short and long exposures. British Journal of Psychology, 51, 119-125.

Morton, J. (1969). The interaction of information in word recognition. Psychological Review, 76, 165-178.

NielseN, G. D., \& SMITH, E. E. (1973). Imaginal and verbal representations in short-term recognition of visual forms. Joumal of Experimental Psychology, 101, 375-378.

PaAp, K. P., Newsome, S. L., McDonald, J. E., \& Schvaneveldt, R. W. (1982). An activation-verification model for letter and word recognition. The word superiority effect. Psychological Review, 89, 573-594.

PAIvio, A. (1971). Imagery and verbal processes. New York: Holt, Rinehart \& Winston.

Paimer, S. E. (1975). The effects of contextual scenes in the identification of objects. Memory \& Cognition, 3, 519-526.

Perrett, D., Rolls, E., CAAN, W. (1982). Visual neurones responsive to faces in the monkey temporal cortex. Experimental Brain Research, 47, 329-342.

Rumelhart, D. E., MCClelland, J. L. (1982). An interactive ac- 
tivation model of context effects in letter perception: Part 2. The contextual enhancement effect and some tests and extensions of the model. Psychological Review, 89, 60-94.

SchneIder, W., \& ShIFFrin, R. M. (1977). Controlled and automatic human information processing: 1. Detection, search and attention. Psychological Review, 84, 1-66.

SeYmour, P. H. K. (1979). Human visual cognition. London: Collier Macmillan.

SMITH, E. E. \& NiELSEN, G. D. (1970). Representations and retrieval processes in short-term memory. Journal of Experimental Psychology, 85, 397-405.

Spelke, E., Hirst, W., \& Neisser, U. (1976). Skills of divided attention. Cognition, 4, 215-230.

VAN SANTEN, J. P. H., \& Jonides, J. (1978). A replication of the facesuperiority effect. Bulletin of the Psychonomic Society, 12, 378-388.

WALKER-SMITH, G. J. (1978). The effects of delay and exposure duration in a face recognition task. Perception \& Psychophysics, 24, 63-70.

Weisstein, N., \& Harris, C. S. (1974). Visual detection of line segments: An object superiority effect. Science, 186, 752-755.

\section{NOTES}

1. Homa et al. (1976) gave a much briefer exposure, but a pilot study revealed that only chance recognition was achieved at the 60 -msec exposures they used. The reason for the discrepancy probably lies in the lower contrast and luminance displays used in the present study. There is also the possibility that the much shorter rise-and-decay constants of the Electronic Developments tachistoscope lamps were important (Mollon \& Polden, 1978).

2. The visual mask was used to replicate as closely as possible the conditions of the Homa et al. (1976) study. At the exposure durations used in the present study, the visual mask cannot be effective in preventing further processing, and one would expect to find perceptual grouping and superiority effects similar to those without the mask present (Breitmeyer, 1984, pp. 233-248).

(Manuscript received March 11, 1986; revision accepted for publication September 16, 1986.) 